\title{
PPDM DESA SARUMANA SEBAGAI PUSAT PENGEMBANGAN KAKAO RAKYAT DI SULAWESI TENGAH
}

\author{
Flora Pasaru ${ }^{1 *}$, Yosep Patadungan ${ }^{1}$, dan Moh. Hibban Toana ${ }^{1}$ \\ ${ }^{1}$ Program Studi Agroteknologi, Fakultas Pertanian Universitas Tadulako, \\ Jln. Soekarno Hatta Km. 9 Palu 94118 Sulawesi Tengah Indonesia \\ Email : florapasaru45@yahoo.co.id
}

\begin{abstract}
ABSTRAK
Kakao merupakan salah satu komoditas unggulan sektor perkebunan yang turut memberi andil dalam meningkatkan perekonomian masyarakat terutama di pedesaan. Banyak faktor yang menyebabkan produktivitas kakao saat ini mengalami penurunan antara lain: (1). tanaman kakao rakyat sudah berumur lebih dari 15 tahun; (2) serangan hama penggerek buah kakao (PBK) Conopomorpha cramerella (3). serangan penyakit pembuluh kayu atau vascular streak dieback(VSD) (4). serangan penyakit busuk buah Phythopthora palmivora dan (5) kurang perawatan oleh petani.Hasil rembug dengan anggota kelompok tani mitra bersama dengan kepala desa disepakati untuk menyelesaikan permasalahan yang dianggap prioritas untuk segera diatasi dalam pelaksanaan program pengembangan desa mitra (PPDM). Program Pengembangan Desa Mitra (PPDM) bertujuan untuk mengembangkan Desa Sarumana sebagai pusat kakao rakyat di Sulawesi Tengah melalui peningkatkan pengetahuan dan ketrampilan anggota masyarakat dalam perakitan teknologi budidaya berdaya hasil tinggi, teknologi pengendalian hama dan penyakit, teknologi pengembangan pupuk organik untuk kesinambungan produksi kakao, dan teknologi penanganan hasil kakao agar dapat bernilai jual tinggi. Metode yang diterapkan dalam pencapai tujuan tersebut adalah: pelatihan, demonstrasi teknologi, demplot, pendampingan dan pembinaan yang dilakukan secara partisipatif dan pemberdayaan masyarakat dalam pengembangan kakao berdaya hasil tinggi. Pada pelaksanaan pelatihan diberikan materi tentang teknik grafting, pengendalian hama PBK menggunakan predator Dolichoderus thoracicus, pengendalian penyakit Vascular Streak Dieback (VSD) dengan mikroba antagonis, pengendalian penyakit busuk buah kakao dengan biofungisida, dan pembutan pupuk organik berbahan baku limbah kulit buah kakao. Hasil yang diperoleh bertambahnya wawasan dan pengetahuan masyarakat sasaran melalui programpenyuluhan, pelatihan dan pendampingan serta pemberdayaan, serta terjadi perubahan sikap maupun pola pikir dari masyarakat khususnya kelompok tani mitra tentang pentingnya pengembangan kakao. Terbentuknya 2 demplot yakni demplot teknologi pengendalian organisme pengganggu tanaman (OPT) dengan sarang buatan Dolichoderus thoracicus dan infus akar Trichoderma cair, dan demplot budidaya tanaman kakao dengan teknologi side grafting pada tanaman kakao, terbentuknya 2 unit bak pengomposan pada kelompok tani mitra, bertambahnya skill masyarakat dalam mengelola sumber daya alam maupun limbah pertanian melalui program pelatihan pembuatan pupuk kompos berbahan baku limbah kulit buah kakao,dan pupuk organik cair (MOL) dari limbah rumah tangga.
\end{abstract}

Katakunci: Rakitan teknologi pengembangan kakao rakyat, pengendalian hama dan penyakit tanaman kakao, penanganan hasil kakao.

\section{Pendahuluan}

Desa Sarumana Kecamatan Palolo termasuk sentra pengembangan kakao di Kecamatan Palolo. Umumnya penduduk di desa tersebut melakukan budidaya kakao karena daerah tersebut sangat mendukung untuk pertumbuhan tanaman, yaitu beriklim panas, sedikit hari hujan dan berada pada ketinggian tempat sekitar $157 \mathrm{~m}$ dpl. Meskipun demikian produktivitas kakao yang dicapai saat ini masih tergolong rendah jika dibandingkan dengan rata-rata produksi kakao nasional yang mencapai 920 $\mathrm{kg} / \mathrm{ha} /$ tahun (Ditjenbun,2009).

Banyak faktor/permasalahan yang menyebabkan produktivitas kakao di desa Sarumana terus menurun antara lain: (1). tanaman kakao rakyat sudah berusia tua (tanaman sudah berumur lebih dari 15 tahun); (2) serangan hama penggerek buah kakao (PBK) Conopomorpha cramerella (3). serangan penyakit busuk buah Phythopthora palmifora (4). serangan penyakit pembuluh 
Abditani: Jurnal Pengabdian Masyarakat 3 (1) 27-37

e-ISSN: 2622-4690

p-ISSN: 2622-4682

kayu atau Vascular Streak Dieback(VSD),(5) kurang perawatan olehpetani, (6) Sarana produksi seperti pupuk dan pestisida semakin mahal dan pada waktu-waktu tertentu seringkali tidak tersedia di pasaran menyebabkan petani tidak melakukan pemupukan dan pengendalaian hamapenyakit (tidak dilakukan perawatan tanaman), (7) Ketergantung petani pada pupuk kimia dan pestisida kimia sangat tinggi sehingga biaya usaha tani semakin mahal, (8) adanya limbah kulit buah kakao yang dapat menjadi sumber penularan berbagai macam penyakit, dan (9) rendahnya mutu biji kakao rakyat yang berakibat pada rendahnya nilai jual yang diterima oleh masyarakat /petani (Gambar 1).

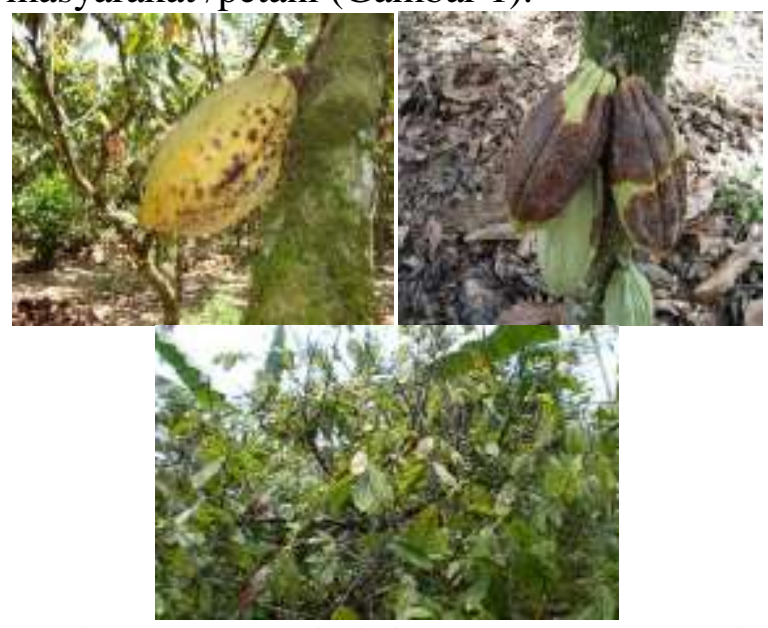

Gambar 1. a. Buah kakao terserang PBK, b. Buah kakao terserang busuk buah, c. Tanaman kakao yang terserang VSD

Kerugian akibat serangan hama PBK di Sulawesi Tengah telah dilaporkan mencapai Rp. 80,7 milyar yang meliputi penurunan produksi sebesar $60-80 \%$ dan penurunan kualitas biji mencapai 35-58\% (BP4 Sulteng, 2008), sedangkan kehilangan hasil akibat serangan VSD belum banyak dianalisis, namun dari pengamatan di lapangan banyak tanaman menjadi gundul dan berakibat pada sedikitnya buah yang diproduksi. Penyakit VSD nampaknya lebih berbahaya bila dibandingkan dengan serangan PBK, karena serangan VSD akan memperlemah tanaman yang berakibat tidak hanya pada penurunan produksi tanaman, tetapi juga secara perlahan dapat mematikan tanaman secara keseluruhan.

Selain permasalahan produksi kakao yang dihadapi oleh masyarakat/petani di Desa Sarumana, permasalahan sumberdaya manusia dan manajemen sangat mempengaruhi hasil produksi kakao. Di Desa Sarumana terdapat beberapa kelompok tani kakao yang secara intens melakukan kegiatan budidaya kakao, namun produksi yang diperoleh belum memberikan hasil yang menggembirakan karena adanya berbagai permasalahan seperti diatas Untuk kesinambungan dan peningkatan produktivitas kakao pada pertanaman rakyat dapat tempuh dengan tindakan budidaya sehat, sedangkan untuk mengantisipasi kerugian petani akibat gangguan hama dan penyakit maka perlu dilakukanpengendalian yang hama dan penyakit tanaman kakao secaraberkelanjutan.

Program Pengembangan Desa Mitra (PPDM) akan melaksanakan kegiatan pembinaandan pendampingan masyarakat khususnya petani kakao agar dapat mengembalikan status Desa Sarumana sebagai Pusat Pengembangan Kakao Rakyat di Sulawesi Tengah.

Pembinaan dan pendampingan tersebut terutama adalah yang berkaitan dengan perakitan teknologi produksi, teknologi pengendalian hama dan penyakit serta teknologi penanganan hasil kakao agar dapat diperoleh mutu biji kakao yang baik dan bernilai jual tinggi, untuk meningkatkan pendapatan masyarakat.Kegiatan PPDM telah mendapatkan persetujuan dari Kepala Desa Sarumana dan ketua-ketua kelompok tani kakao yang akan menjadi mitra dalampelaksanaan PPDM, sebagaimana yang tertuang dalam surat pernyataan kepala desa dan ketua kelompok tani tentang kesiapannya dalam mendukung program PPDM tersebut.

Adapun tujuan dari program PPDM yakni mengembangkan Desa Sarumana sebagai desa sentra kakao rakyat di Kecamatan Palolo Kabupten Sigi. 


\section{Solusi dan Target Luaran}

Adapun solusi yang ditawarkan dalam setiap permasalahan yang di hadapi di Desa Sarumana Kec. Palolo Kab. Sigi dalam kegiatan Program Pengembangan Desa Mitra (PPDM) sebagai berikut: 1). melakukan kegiatan pendidikan dan pelatihan serta transfer ipteksdalam bidang teknologi produksi, yang bertujuanuntuk meningkatkan pengetahuan, ketrampilan dan keahlian masyarakat dengan menyampaikan materi dan mempraktekkan setiapkegiatan, 2)melakukan kegiatan pendidikan dan pelatihan dalam bidangmanajemen, yang bertujuan untuk meningkatkan pengetahuan, ketrampilan dan keahlian masyarakat dalam mengatur pemasaran hasil produksi dengan menyampaikan materi dan mempraktekkan setiapkegiatan, dan 3) melakukan kegiatan Pendampingan dan Pembinaan. Adapun luaran yang ditargetkan dari pelaksanaan PPDM disajikan pada Tabel 1 :

Tabel 1. Luaran dan indikator capaian setiap kegiatan

\begin{tabular}{|c|c|c|}
\hline Aktivitas & Luaran & Indikator Capaian \\
\hline \multicolumn{3}{|c|}{ TAHUN I (2019) } \\
\hline $\begin{array}{l}\text { Pembentukan kelompok } \\
\text { pembudidaya kakao }\end{array}$ & Kelompok budidaya kakao & $\begin{array}{lcc}\text { Terbentuk } & 2 & \text { kelompok } \\
\text { Pembudidaya tanaman kakao }\end{array}$ \\
\hline $\begin{array}{lr}\text { Pelatihan } & \text { teknologi } \\
\text { produksi, } & \text { teknologi } \\
\text { pengendalian } & \text { hama } \\
\text { danpenyakit, serta } & \text { teknologi } \\
\text { fermentasi } & \end{array}$ & $\begin{array}{l}\text { Peningkatan pengetahuan } \\
\text { petani tentang teknologi } \\
\text { budidaya, teknologi PHT } \\
\text { dan teknologi pasca panen }\end{array}$ & $\begin{array}{l}\text { Kelompok mampu Melaksanakan } \\
\text { budidaya tanaman kakao dan } \\
\text { pengendalian OPT serta } \\
\text { fermentasi biji kakao }\end{array}$ \\
\hline $\begin{array}{l}\text { Demplot budidaya kakao } \\
\text { berdaya hasil tinggi }\end{array}$ & $\begin{array}{l}\text { Tanaman kakao di areal } \\
\text { demplotmenjadi } \\
\text { pembelajaran masyarakat }\end{array}$ & $\begin{array}{l}\text { Terbentuknya percontohan } \\
\text { tanaman kakao yang berdaya hasil } \\
\text { tinggi }\end{array}$ \\
\hline $\begin{array}{l}\text { Sekolah lapang komoditi } \\
\text { kakao }\end{array}$ & $\begin{array}{l}\text { Model pelaksanaan sekolah } \\
\text { lapang yang sesuai dengan } \\
\text { kearifan lokal }\end{array}$ & $\begin{array}{l}\text { Terbentuk } 2 \text { kelompok } \\
\text { Pembudidaya tanaman kakao yang } \\
\text { ahli PHT }\end{array}$ \\
\hline
\end{tabular}

\section{Metode Pelaksanaan}

\section{Metode Pendekatan yangDitawarkan}

Untukmendukungrealisasiprogram,mak aakandilakukankegiatanberupa: penyuluhan, pendidikan dan pelatihan, demplot, rancang bangun teknologi, dan pelatihan manajemen produksi dan usaha serta pendampingan anggota kelompok usaha mitra yang akan dilaksanakan dengan MetodePartisipatif.

\section{Rencana KegiatanTahunan}

Program Desa Sarumana sebagai pusat pengembangan kakao rakyat di Sulawesi Tengah, direncakan berlangsung selama 3 Tahun, dengan rancangan kegiatan yang telah disepakati bersama antara tim pengsul dengan desa mitra (Kepala Desa) serta kelompok mitra yakni sebagai berikut:
Tahun Pertama (Tahun 2019); berupa peningkatan kapasitas sumberdaya manusia dalam pengembangan kakao rakyat dengan kegiatan sebagai berikut : 1) Pelatihan teknik sambung samping dan sambung pucukkakao, 2) Pelatihan pengembangan teknik pengendalian hamakakao, 3) Pelatihan pengembangan teknik pengendalian panyakit tanamankakao, 4) Pelatihan SL-PHT komoditi kakao, 5) Pelatihan teknik peningkatan mutu bijikakao, 6) Pelatihan teknik budidaya tanaman kakao berdaya hasiltinggi, 7) Pelatihan manajemen organisasi kelompoktani, 8) Pelatihan manajemen keuangan kelompoktani, 9) Pembuatan demplot pertanaman kakao berdaya hasiltinggi, dan 10) Pengembangan berbagai jenis saprodi untuk tanaman kakao. 


\section{Pelaksanaan Kegiatan}

Pelatihan, demonstransi teknologi, dan kerja praktek/rancang bangun teknologi pertanian

Pada kegiatan kerja praktek akan dilaksanakan dengan membagi peserta pelatihanmenjadi6kelompokdenganmasingmasingkelompokterdiridari5orang yang akan didampingi oleh Tim pelaksana PPDM. Kegiatan yang akan dilaksanakan pada kerja praktek sebagai berikut:

1. Teknologi pengendalian PBK dengan Predator Dolichoderussp.

2. Teknologi pengendalian penyakit VSD dan busuk buah dengan dengan pemangkasan sanitasi dan mikrobaantagonis

3. Teknologi pembuatan biofungisida berbahan aktif Trichoderma sp.

4. Teknologi pembuatan pupuk organik berbahan baku limbah kulit buah kakao

Kerja Praktek / rancang bangun teknologi tersebut di atas dilakukan sedemikian rupa agar peserta pelatihan dapat mentransfer teknologi tersebut.

\section{Teknologi pengendalian PBK dengan Predator Dolichoderus sp.}

Untuk melakukan pengendalian hama PBK dengan predator Dolichoderus sp, diawali dengan pengembangan predator Dolichoderus sp melalui pembuatan sarang buatan agar dapat berkembang dengan baik. Sarang buatan yang akan digunakan adalah jenis sarang yang terbuat dari batang bambu dan daun kelapa. Setelah diperagakan teknik membuat sarang buatan tersebut selanjutnya dilakukan demonstrasi pembuatan sarang buatan untuk Dolichoderus sp. dan teknik pemasangansarangbuatantersebutpadapertan amanbuahkakaoyangefektif (Gambar 2),baik dalam usaha meningkatkan jumlah populasi Dolichoderus sp tersebut maupun meningkatkan predasinya terhadap hama PBK.

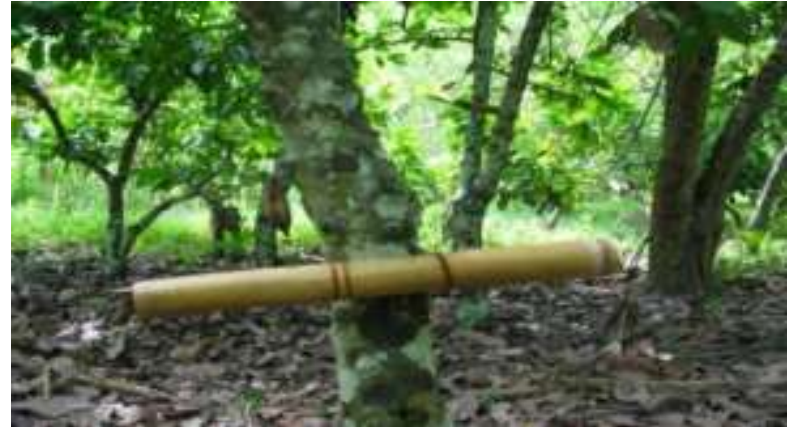

Gambar 2. Pengendalian PBK dengan menggunakan semut predator

\section{Teknologi Pengendalian Penyakit VSD}

Penyakit VSD disebabkan oleh jamur Oncobasidium theobromae dengan Gejala Penyakit adalah klorosis yang pada daun tampak menguning dengan bercak- bercak berwarna hijau. Biasanya daun tersebut terletak pada seri daun kedua atau ketiga dari titik tumbuh. Daun-daun yang menguning akhirnya gugur sehingga tampak gejala rantingbolong-bolong (Gambar 3).Intensitas serangan ditentukan berdasarkan persentase ranting sakit dan kerusakan pada xylem yaitu serangan ringan jika jumlah ranting sakit kurang dari $10 \%$ dan jamur yang menyerang hanya sampai pada cabang tersier, serangan sedang yaitu jumlah ranting sakit 10-30\% dan jamur yang menyerang sampai pada cabangsekunderdanSeranganberatjumlahrant ingsakitlebihdari30\%danjamur yangmenyerangsampaipadacabangprimerata ubatangpokok.Pangkasansanitasi dilakukan dengan cara memotong ranting sakit sampai batas garis cokelat pada xylem ditambah $30 \mathrm{~cm}$ (Gambar 4).

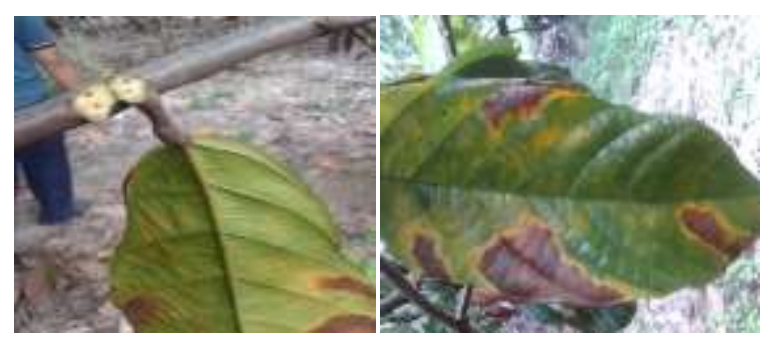

Gambar 3. Gejala penyakit Vascular Streak Dieback (VSD) pada tanaman kakao 


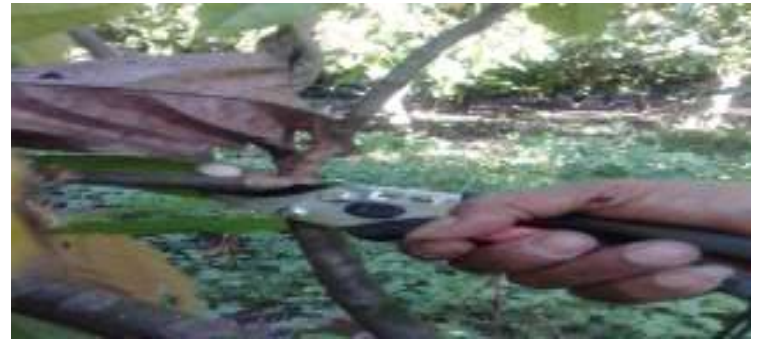

Gambar 4. Pemotongan ranting yang terserang VSD

Teknologi pembuatan pupuk organik plus biofungisida berbahan aktif jamur antagonis Trichoderma sp.

Diawali dengan perbanyakan jamur menggunakan tongkol jagung. Setelah jamur sudah siap, dilanjutkan pembuatan pupuk organik plus biotek Trichoderma sp. yang berperan sebagaibiofungisida.

Teknologi pembuatan pupuk organik berbahan baku limbah kulit buah kakao

Diawali dengan mencacah limbah kulit buah kakao sampai berukuran kecil kemudian ditumpuk sehingga menjadi hancur. Selanjutnya dilakukan penambahan mikroba EM4 serta larutan gula pasir dan diaduk merata, lalu dimasukkan kedalam kotak/bak fermentasi kemudian ditutup dengan karung. Selanjutnya dilakukan fermentasi kulit buah kakao selama 3-4 Minggu.

\section{Pendampingan}

Pendampingan dilakukan untuk memastikan bahwa teknologi yang disampaikan kepada petani kakao dapat dilaksanakan dengan baik sehingga hasil yang diperoleh dapat mencapai sasaran yaitu peningkatan produktivitas kakao dengan dengan penggunaan sarana produksi berbahan baku lokal

\section{Partisipasi mitra dalam pelaksanaan program}

Dalam pelaksanaan PPDM

ini,kelompok sasaran akan terlibat dalam proses penyediaan peralatan bahan yang diperlukan yang tersedia di lokasi sasaran, dan keikutsertaan peserta dalam melakukan rakitan teknologi dengan memperhatikan arahan dari tim pelaksana PPDM, sehingga setelah kegiatan ini selesai kelompok sasaran tersebut dapat mandiri dalam menjalankan kegiatan usaha taninya menggugnakan raakitan teknologi yang telah dipraktekkantersebut.

\section{Hasil dan Pembahasan}

\section{Program Kegiatan}

Adapun program kegiatan PPDM yang telah dilaksanakan di Desa Sarumana Kecamatan Palolo Kabupaten Sigi, sebagai berikut :

1. Sosialisasi Program

Tim pengabdi telah melaksanakan Sosialisasi Program Pengembangan Desa Mitra (PPDM), pada tanggal 06-07 April 2019 di kantor Desa Sarumana. Hal ini bertujuan untuk mengembangkan Desa Sarumana sebagai pusat kakao rakyat. Jumlah peserta sosialisasi sebanyak 25 orang, yang terdiri dari masyarakat, anggota kelompok tani mitra, kepala desa, dan penyuluh pertanian lapangan (Gambar 5).

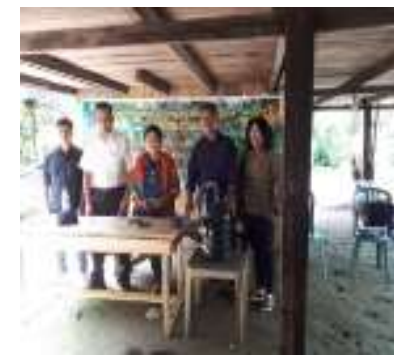

Gambar

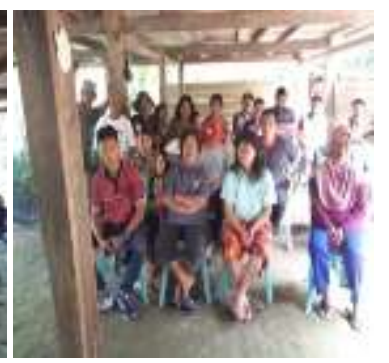

Sosialisasi Program Pengembangan Desa Mitra di Desa Sarumana Kec. Palolo Kab. Sigi

\section{Penyuluhan}

Penyuluhan dilaksanakan mulai tanggal 19 sampai dengan 20 April 2019, dengan topik Pengembangan Kakao Rakyat Untuk Meningkatkan Produksi di Desa Sarumana Kec. Palolo Kab. Sigi di Kantor Desa.

Penyuluhan ini bertujuan untuk meningkatkan pengetahuan petani kakao dalam perakitan teknologi budidaya berdaya hasil tinggi. Jumlah peserta yang ikut dalam penyuluhan sebanyak 50 Orang yang terdiri dari kepala desa sarumana, anggota kelompok tani mitra, masyarakat, dan 
penyuluhan pertanian lapangan (PPL) (Gambar 6).
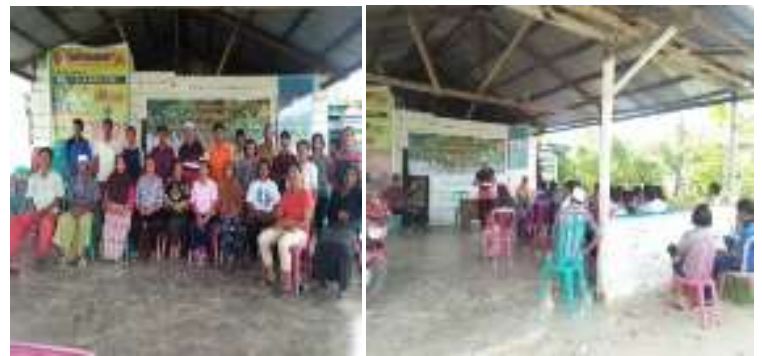

Gambar 6. Kegiatan penyuluhan pengembangan kakao rakyat untuk meningkatkan produksi di Desa Sarumana Kec. Palolo Kab. Sigi
3. Pelatihan, demonstransi teknologi, dan kerja praktek/rancang bangun teknologipertanian

Pada kegiatan pelatihan/ kerja praktek di lapangan akan dilaksanakan dengan membagi peserta pelatihan menjadi 6 kelompok dengan masing-masing kelompok terdiri dari 5 orang yang akan didampingi oleh Tim pelaksana PPDM. Kegiatan yang akan dilaksanakan pada kerja praktek pada Tabel 2.

Tabel 2. Kegiatan pelatihan/kerja praktek

\begin{tabular}{clc}
\hline No. & \multicolumn{1}{c}{ Materi Pelatihan } & Narasumber \\
\hline 1. & $\begin{array}{l}\text { Teknikpengendalian PBK dengan predator } \\
\text { Dolichoderus sp. }\end{array}$ & Tim PPDM \\
2. & $\begin{array}{l}\text { Teknologi pengendalian penyakit VSD dan } \\
\text { busuk buah dengan dengan pemangkasan }\end{array}$ & Tim PPDM \\
& $\begin{array}{l}\text { sanitasi dan mikrobaantagonis } \\
\text { Teknologi pembuatan biofungisida berbahan Aktif }\end{array}$ & Tim PPDM \\
Trichoderma sp. & $\begin{array}{l}\text { Teknik pembuatan pupuk organik berbahan baku limbah } \\
\text { kulit buah kakao }\end{array}$ & Tim PPDM \\
5. Teknik peremajaan tanaman kakao dengan side grafting & Tim PPDM \\
\hline
\end{tabular}

Kerja praktek/rancang bangun teknologi tersebut di atas dilakukan sedemikian rupa agar peserta pelatihan dapat mentransfer teknologi tersebut.

Adapun kegiatan pelatihan/kerja lapangan yang dilakasanakan di Desa Sarumana Kec. Palolo Kab. Sigi sebagai berikut:

\section{A. Teknologi pengendalian PBK dengan predator Dolichoderus sp.}

Kegiatan pelatihan/kerja praktek pengembangan semut Dolichoderus untuk pengendalian hama PBK di Desa Sarumana Kec. Palolo di laksanakan pada tanggal 9-11 Juni 2019 (Gambar 7). Hal ini bertujuan untuk meningkatkan pengetahuan dan keterampilan petani kakao dengan perakitan teknologi pemanfaatan sarang buatan dari potongan bambu dan daun kelapa sebagai sarang buatan untuk semut $D$. thoracicus untuk pengendalian hama PBK. Untuk melakukan pengendalian hama PBK dengan predator Dolichoderus sp, diawali dengan pengembangan predator Dolichoderus sp. melalui pembuatan sarang buatan dengan tujuan agar semut tersebut dapat berkembang dengan baik

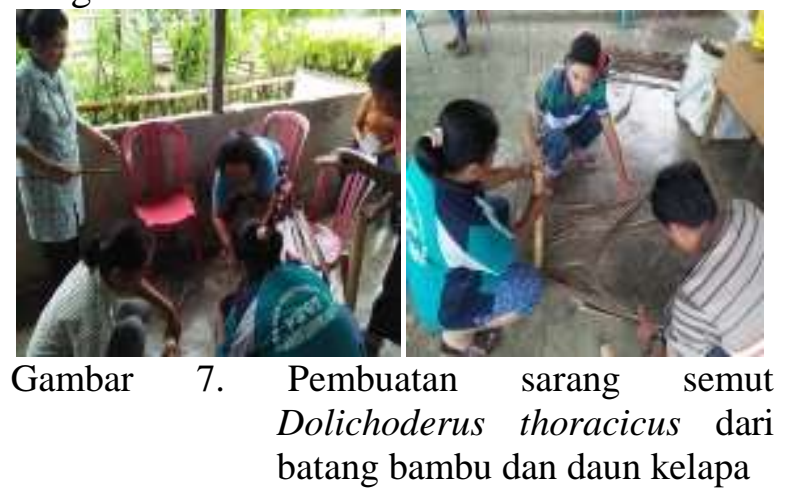

B. Teknologi pengendalian penyakit VSD dan busuk buah dengan pemangkasan sanitasi dan mikroba antagonis

Penyakit VSD merupakan salah satu kendala utama dalam budi daya kakao karena perkembangan dan penyebarannya yang cepat. Di Indonesia penyakit ini pertama kali ditemukan pada tahun 1983 di 
Pulau Sebatik Kalimantan Timur dan pada tahun 2006 sudah tersebar dihampir seluruh pertanaman kakao di Indonesia (Halimah dan Sukamto 2006), tahun 2009 di Jembrana Bali (Dewi, 2011), dan tahun 2013 di Sumatera Utara (Dhana et al. 2013).

Penyakit Vascular streak Dieback disebabkan oleh jamurOncobasidium theobromae dengan gejala penyakitadalah klorosis yang pada daun tampak menguning dengan bercak-bercak berwarna hijau. Biasanya daun tersebut terletak pada seri daun kedua atau ketiga dari titik tumbuh, pada bekas duduk daun terlihat tiga noktah berwarna cokelat. Gejala lanjut menunjukkan daun gugur, ranting gundul, dan pucuk mati. Tanaman yang terserang akan meranggas dan kemudian mati secara perlahan (Gambar 4).

Selain penyakit VSD, penyakit busuk buah dapat menyebabkan penurunan hasil produksi. Hal ini sebabkan karena kurangnya perawatan atau sanitasi yang dilakukan oleh petani kakao di Desa Sarumana Kec. Palolo Kab. Sigi. Maka dari itu, dengan adanya kegiatan PPDM di desa Sarumana masyarakat khususnya kelompok tani mitra dapat mengetahui cara atau teknik pengendalian penyakit yang ramah lingkungan, yaitu dengan cara sanitasi dan pemanfaatan jamur antagonis Trichoderma sp. dan B. bassiana. Maka dari itu dilakukan kegiatan pelatihan Sistem Budidaya dan Pengendalian OPT Tanaman Kakao di Desa Sarumana Kec.Palolo Kab. Sigi pada tanggal 30 April 2019 sampai dengan 02 Mei 2019, dengan tujuan untuk mendampingi kelompok tani mitra dalam cara pengaplikasian cendawan Trichoderma sp.pada tanaman kakao sebagai agensi hayati pengendalian busuk buah kakao di tempat yang telah disiapkan (Gambar 8).

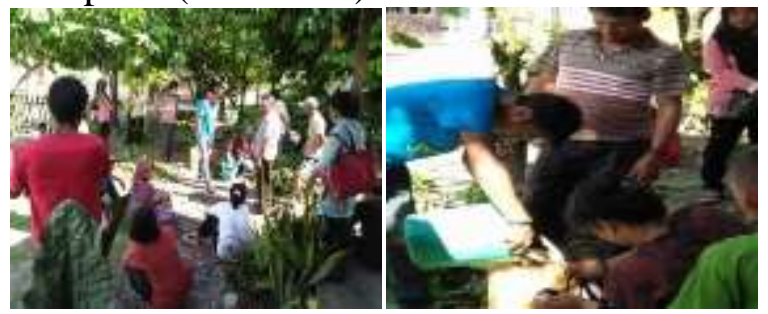

Gambar 8. Jamur antagonis ke tanaman kakao di Desa Sarumana
C. Teknologi pembuatan biofungisida berbahan Aktif Trichoderma sp.

Pelatihan pengembangan agens hayati untuk pengendalian penyakit kakao di Desa Sarumana Kec. Palolo Kab. Sigi di laksanakan pada tanggal 16-18 Juni 2019, dengan tujuan untuk meningkatkan pengetahuan petani kakao dalam mengendalikan hama atau penyakit pada tanaman kakao dengan cara pembuatan perbanyakan cendawan Beauveria basianna dan cendawan Trichoderma, sp.sebagai agensi hayati untuk pengendalian yang ramah lingkungan, dan agar petani kakao tidak tergantung dengan penggunaan pestisida kimia sebagai satu-satunya cara pengendalian.

Jamur Trichoderma sp. merupakan jamur antagonis yang dapat mengendalikan penyakit pembuluh kayu yang disebabkan jamur Oncobasidium theobromae dan penyakit busuk buah yang disebabkan jamur $P$. palmivora, yang diketahui bahwa kedua penyakit ini dapat menyebabkan penurunan produksi kakao. Selain jamur Trichoderma sp., jamur B. bassiana dapat menggendalikan hama pada tanaman kakao, salah satu hama yang dapat dikendalikan yakni hama penggerek buah $C$. cramerella, yang diketahui bahwa hama ini dapat menyebabkan penurunan biji kakao baik secara kuantitas dan kualitas (Agrios, 2005).

Jamur antagonis ini sangat mudah ditumbuhkan pada berbagai media tumbuh, salah satu media tumbuh yang digunakan yakni jagung giling yang berstektur kasar, akan tetapi kedua jamur antagonis ini memiliki sifat tumbuh yang berbeda, seperti jamur Trichoderma sp. memiliki sifat tumbuh yang tidak suka asam, sebaliknya jamur B. bassiana lebih suka dengan media tumbuh yang asam (Gambar 9). Selain jamur antagonis dapat ditumbuhkan di media jagung dan beras, jamur antagonis Trichoderma sp. dan B. bassiana juga dapat dibuat dalam bentuk cair, dengan media tumbuh air rebusan ketang, gula merah, dan inokulum Trichoderma sp. dengan masa inkubasi 14 hari (Gambar 10). 


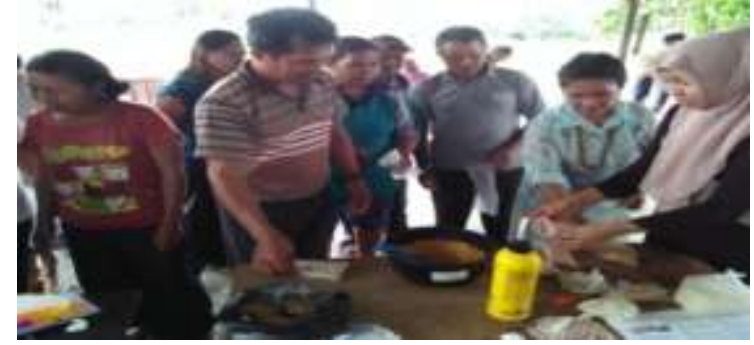

Gambar 9. Cara perbanyakan jamur antagonis dengan menggunakan media jagung

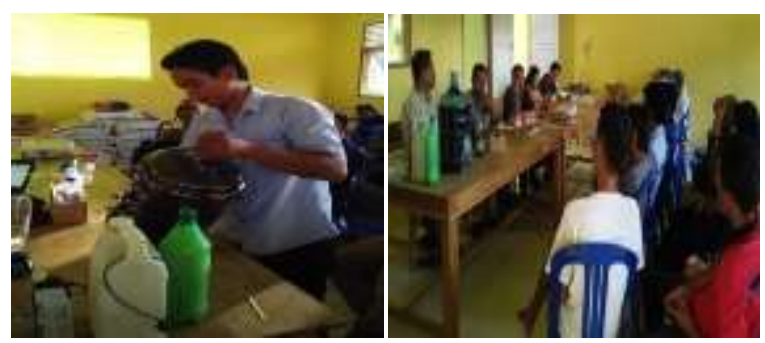

Gambar 10. Cara pembuatan jamur Trcihoderma sp. cair

D. Teknik pembuatan pupuk organik berbahan baku limbah kulit buah kakao

Pelatihan pengembangan pupuk organik berbahan baku limbah kulit buah kakao diDesa Sarumana Kec. Palolo Kab. Sigi dilaksanakan pada tanggal 26-28 Mei 2019, dengan tujuan untuk meningkatkan pengetahuan dan keterampilan petani kakao dalam memanfaatkan limbah kulit kakao yang dapat dimanfaatkan sebagai pupuk organik yang ramah lingkungan (Gambar $11)$.

Limbah pertanian meliputi semua hasil proses pertanian yang tidak termanfaatkan atau belum memiliki nilai ekonomis. Salah satu cara untuk memanfaatkan limbah pertanian adalah dengan dijadikan kompos, seperti halnya dengan kulit buah kakao. Pupuk organik yang digunakan adalah pupuk organik yang berasal dari pemanfaatan limbah kulit kakao yang terlebih dahulu dikomposkan dengan menggunakan aktivator EM-4. Sebagai bahan organik, kulit buah kakao mempunyai komposisi hara dan senyawa yang sangat potensial sebagai medium tumbuh tanaman. Kadar air untuk kakao lindak sekitar $86 \%$, dan kadar bahan organiknya sekitar 55,7\% (Soedarsono. dkk, 1997).

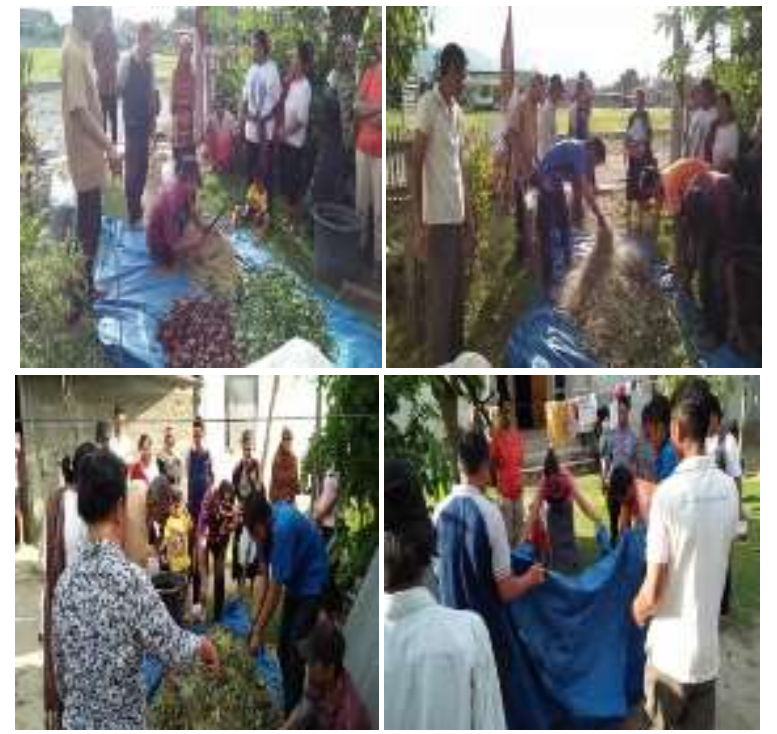

Gambar 11. Cara pembuatan pupuk kompos berbahan baku limbah kulit buah kakao

\section{E. Teknik peremajaan tanaman kakao dengan side grafting}

Pelatihan budidaya kakao dengan metode side grafting dilaksanakan pada tanggal 19-21 Mei 2019, dengan tujuan untuk peningkatan pengetahuan dan keterampilan anggota masyarakat/kelompok tani mitra dalam perakitan teknologi budidaya dengan metode side grafting untuk kesinambungan produksi kakao (Gambar 12). Sambung samping (side grafting) merupakan suatu teknik perbanyakan tanaman secara vegetatif dengan perlakuan menyambungkan tanaman sejenis (satu family) dengan menggunakan mata tunas (entries) dari klon unggul yang dipotong dan ditempelkan pada batang tanaman kakao dewasa (Syakir, 2010)

Keuntungan teknologi sambung samping tanaman kakao adalah mutu biji dan ketahanan terhadap hama dan penyakit dengan penggunaan klon unggul, lebih mudah pelaksanaannya sehingga areal pertanaman kakao dapat di rehabilitasi dalam waktu singkat, tanaman kakao lebih cepat berproduksi, saat batang sambungan (entries) belum menghasilkan buah/produksi dari batang sambungan (entries) masih dapat dipertahankan hingga batang sambungan berproduksi, batang bawah (batang utama) dapat berfungsi sebagai penaung sementara 
bagi batang sambungan yang sedang tumbuh (Direktorat Jenderal Perkebunan Kementerian Pertanian, 2014).

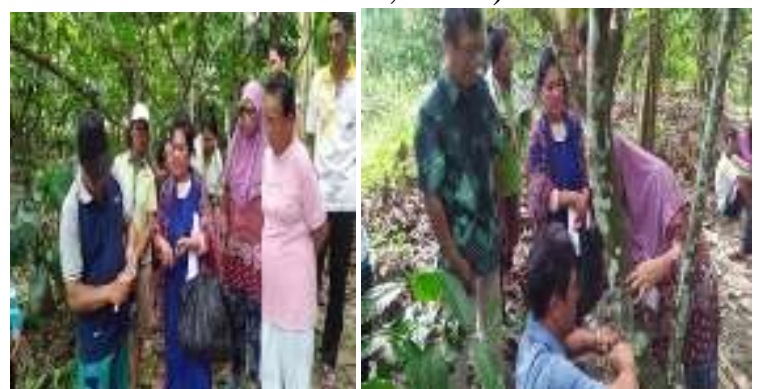

Gambar 12. Cara side grafting di Desa Sarumana Kec. Palolo

\section{Pendampingan}

Pendampingan dilakukan untuk memastikan bahwa teknologi yang disampaikan kepada petani kakao dapat dilaksanakan dengan baik sehingga hasil yang diperoleh dapat mencapai sasaran yaitu peningkatan produktivitas kakao dengan penggunaan sarana produksi berbahan baku lokal. Pendampingan kelompok tani mitra dilakukan sebanyak 5 kali, adapun kegiatan yang dilakukan selama melakukan pendampingan, sebagai berikut :

1. Pendamping kelompok tani mitra dalam pengembangan semut, dilaksanakana pada tanggal 23-25 Juni 2019, dengan jumlah peserta 25 orang masing-masing dari perwakilan kelompok tani Karya Bersama dan kelompok tani Mekar Sari, dengan tujuan mendampingi petani mitra agar terampil dalam pemasangan sarang buatan pada demplot tanaman kakao yang telah disiapkan (sebagai pengendalian PBK ) (Gambar 13).

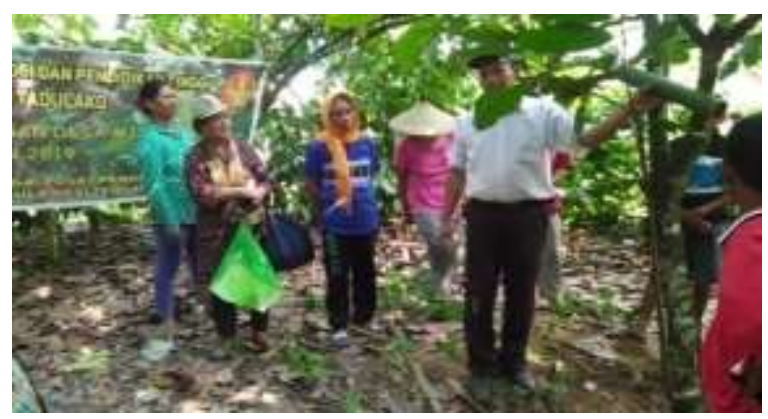

Gambar 13. Pendamping kelompok tani mitra dalam pemasangan sarang buatan semut Dolichoderus sp.
2. Pendampingan kelompok tani mitra dalam pemanfaatan limbah kulit kakao menjadi pupuk organik, yang di laksanakan pada tanggal 30 Juni sampai dengan 02 Juli 2019, dengan jumlah peserta 25 orang masing-masing dari perwakilan kelompok tani Karya Bersama dan kelompok tani Mekar Sari, dengan tujuan mendampingi petani mitra agar terampil dalam cara pembuatan dan pengaplikasian pupuk organik dari limbah kulit kakao pada tanaman kakao (Gambar 14).

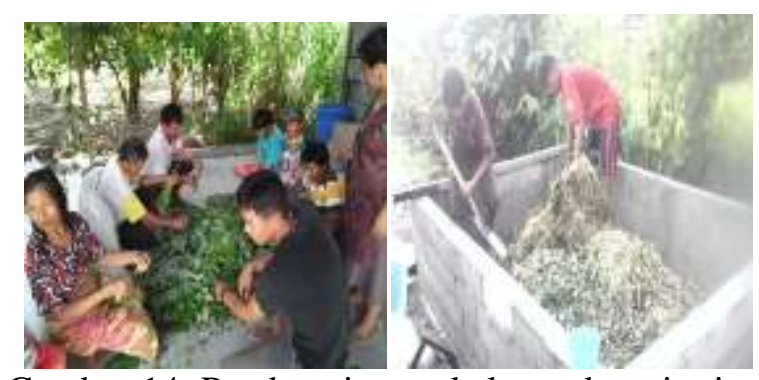

Gambar 14. Pendampingan kelompok tani mitra dalam pembuatan pupuk berbahan baku kulit kakao

3. Pendampingankelompok tani mitra dalam pengendalian penyakit busuk buah kakao, yang telah dilaksanakan pada tanggal 1012 Juli 2019, dengan tujuan mendampingi kelompok tani mitra dalam cara pengaplikasian cendawan Trichoderma sp.pada tanaman kakao sebagai agensi hayati pengendalian busuk buah kakao di tempat yang telah disiapkan (Gambar 15).

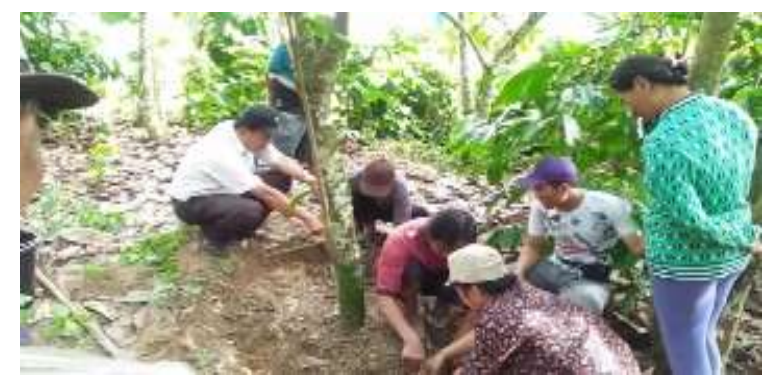

Gambar 15. Pendampingan kelompok tani mitra dalam pengaplikasian Trichoderma sp. dengan infus akar

4. Pendampingan kelompok tani mitra dalam pengendalian penyakit VSD pada tanaman kakao , telah dilaksanakan pada tanggal 24-26 Juli 2019 dengan tujuan mendampingi kelompok tani mitra dalam pengendalian penyakit VSD dengan cara 
pemangkasan dan infus akar cendawan antagonis Trichoderma cair pada tanaman kakao di tempat yang telah disiapkan (Gambar 16)
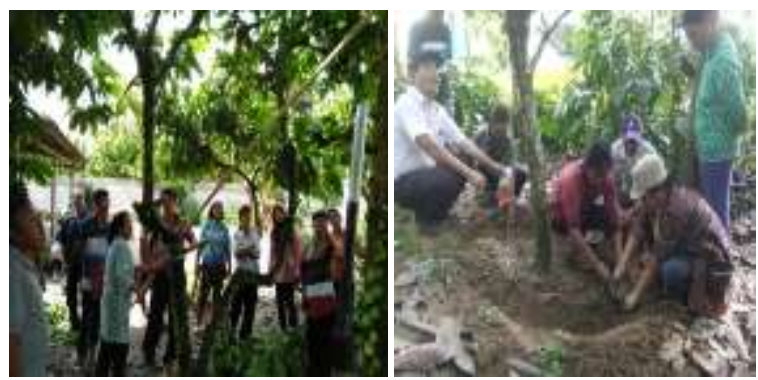

Gambar 16. Pendamping kelompka tani mitra dalam pengendalian penyakit VSD

5. Pendampingan Kelompok Tani Mitra dalam Pengembangan Pupuk Cair MOL di Desa Sarumana Kec. Palolo Kab. Sigi, yang telah dilaksanakan pada tanggal 31 Juli 2019 sampai dengan 02 Agustus 2019, dengan jumlah peserta 25 orang yang dihadiri oleh masing-masing kelompok tani mitra. Pendamping ini dilaksanakan dengan tujuan untuk meningkatkanketerampilan dan pengetahuan kelompok tani mitra dan masyarakat dalam pemanfaatan limbah rumah tangga untuk menjadi pupuk organik cair MOL (Gambar 17).

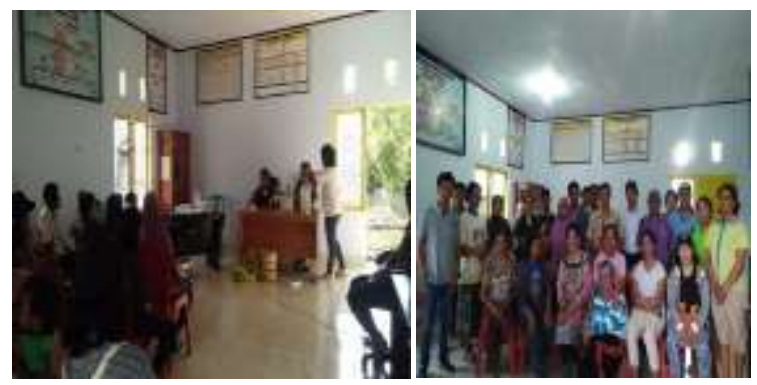

Gambar 17. Pendampingan kelompok tani mitra dalam pembuatan pupuk cair (MOL) berbahan baku limbah rumah tangga

\section{Kesimpulan}

Dari hasil program capaian $70 \%$ yang telah dilaksanakan dilapangan, maka dapat disimpulkan :

1. Kegiatan yang telah dilaksanakan adalah sosialisasi program PPDM, penyuluhan, pelatihan. Demonstrasi teknologi dan kerja praktek/rancang bangun teknologi pertanian. Dalam hal ini kelompok sasaran dibagi 6 kelompok, masingmasing kelompok terdiri 5 orang dan didampingi oleh tim pengabdi.

2. Pelatihan yang telah dilaksanakan adalah teknologi pengendalian PBK dengan perakitan teknologi pemanfaatan saran buatan dari potongan bambu dan daun kelapa sebagai sarang perbanyakan predator semut hitam Dolichoderus thoracicus, teknologi pengendalian penyakit VSD pada tanaman kakao dengan cendawan antagonis Trichoderma sp. dengan cara infus akar, teknologi pengendalian busuk buah kakao $B$. bassiana, teknik pemangkasan, pelatihan side grafting, pembuatan pupuk kompos dengan memanfaatkan limbah kulit kakao dan limbah pertanian, pembuatan pupuk cair dari limbah sayur-sayuran dan buah.

3. Telah terbentuk dua demplot kebun kakao dan dua bak pengomposan pada masingmasing kelompok tani

4. Dari kegiatan pelatihan, pembinaan, dan pendampingan program PPDM yang telah dilaksanakan dapat memotivasi dan menginspirasi masyarakat sasaran program untuk proses peralihan pengetahuan, keterampilan dan perakitan teknologi sebagai indikator bahwa masyarakat sasaran telah mengembangkan pengendalian OPT dengan menggunakan sarang buatan semut predator $D$. thoracicus dan pengendalian penyakit VSD dengan menggunakan Trichoderna sp, cair melalui infus akar.

\section{Ucapan Terima Kasih}

Program PPDM ini dibiayai oleh Direktorat Riset dan Pengabdian kepada Masyarakat, Direktorat Jendral Penguatan Riset dan Pengembangan, Kementrian Riset, Teknologi dan Pendidikan Tinggi dengan Surat Perjanjian Penugasan Pelaksanaan Program Pengabdian Kepada Masyarakat sesuai dengan nomor: 099/SP2H/PPM/DRPM/2019, tanggal 18 Maret 2019. 


\section{Daftar Pustaka}

Agrios, G.N. 2005. Plant Pathology. Fifth Edition. Elsevier Academic Press. USA. $922 \mathrm{p}$.

Dewi FSRK. 2011. Identifikasi molekuler dan keragaman genetik patogen penyebab penyakit pembuluh kayu pada tanaman kakao berdasarkan sekuen Internal Transcribe Spacer (ITS) [tesis]. Bali (ID): Universitas Udayana.

Dhana NP, Lubis L, Lisnawita. 2013. Isolasi cendawan Oncobasidium theobromae (Talbot \& Keane) penyebab penyakit Vascular Streak Dieback pada tanaman kakao di laboratorium. J Online Agroekoteknologi. 2(1):288-293.

Direktorat Jenderal Perkebunan Kementerian Pertanian. 2014. Good Agriculture Practise on Cacao (Teknis Budidaya Kakao yang Baik).

Halimah D, Sukamto S. 2006. Sejarah dan perkembangan penyakit Vascular Streak Dieback (VSD) di Indonesia. Warta Puslit koka Indonesia. 22:107-109.

Syakir, M. 2010. Budidaya dan Pascapanen Kakao. Pusat Penelitian dan Pengembangan Perkebunan 